\title{
Can chronic heart failure induce kidney function damage?
}

\author{
Elzbieta KimaK ${ }^{1 *}$, Marcin Dziedzic $^{1}$, Aleksandra KimaK ${ }^{2}, K_{\text {amila Stachyra }}{ }^{1}$, \\ AndRzej Prystupa ${ }^{3}$, JANusz Solski ${ }^{1}$ \\ ${ }^{1}$ Department of Laboratory Diagnostics, Medical University of Lublin, Chodzki 1, 20-093 Lublin, Poland
2Department of Conservative Dentistry with Endodontic, Medical University of Lublin, Poland
${ }^{3}$ Department of Internal Diseases, Medical University of Lublin, Poland
}

\section{ARTICLE INFO}

Received 11 January 2016

Accepted 21 January 2016

\section{Keywords:}

apoAI,

NTproBNP,

hs-CRP,

lipid hydroperoxide, chronic heart and failure, chronic renal failure.

\begin{abstract}
Accelerated atherosclerosis and increased cardiovascular events have been extensively documented in patients with end stage chronic kidney disease.

The aim of our work was to find evidence supporting the theory that chronic heart failure (CHF) induces renal function damage. In our work, lipids, apolipoprotein (apo)AI, NTproBNP, hsCRP, lipid hydroperoxide (LPO) and creatinine levels were determined in patients with CHF. A total of 37 patients who were diagnosed with $\mathrm{CHF}$, as well as 15 healthy persons, were recruited for the study. The patients were placed into 2 groups: patients with NYHA class 2 and NYHA class 3. Using routine laboratory methods, NTproBNP level, and lipids were measured by way of employing a Cobas Integra analyser, while the concentration of hs-CRP was measured by immunonephelometric methods. Moreover, serum LPO concentration was measured using Cayman's Assay Kit (LPO). The statistical analysis of the obtained results was performed using the nonparametric Kruskal-Wallis test and Spearman's correlation analysis. Our work demonstrated that the CHF patients had significantly decrease concentration of HDL cholesterol and apoAI, but increased NT-pro-BNP, hsCRP and LPO levels. In all CHF patients, a significant positive correlation between NTproBNP concentration and creatinine levels, and a significant negative correlation between NTproBNP concentration and apoAI levels, as well as between concentration of creatinine and apoAI levels, was shown. The study results suggest that variation in the concentration of NTproBNP, LPO, hsCRP, apoAI, creatinine, in addition to chronic heart failure progression, gradually accompany the progress of chronic renal failure. What is more, the disorders may lead to the occurrence of cardiovascular events, consequently, to patient death.
\end{abstract}

\section{INTRODUCTION}

Inflammation and oxidative stress play a critical role in the atherosclerotic process within various vascular beds, starting from endothelial dysfunction, through all stages of plaque build-up, until detrimental clinical ischemic complications [1]. Accelerated atherosclerosis and increased cardiovascular events have been extensively documented in patients with end stage chronic kidney disease (CKD) [1-3]. A graded association between glomerular filtration rate (GFR) and cardiovascular deaths begins with subtle decrease in GFR $\left(<60-80 \mathrm{ml} / \mathrm{min} / 1.73 \mathrm{~m}^{2}\right)$. This imparts an independent risk of death, the occurrence of acute cardiovascular

\footnotetext{
* Corresponding author

e-mail: elzbieta.kimak@wp.pl

tel/fax: (+48 81) 7423813
}

events, hospitalisation, and more cardiovascular complications following a myocardial infarct [4,5]. Even microalbuminuria, in the absence of an apparent decrease in renal function or diabetes, predicts more cardiovascular disease (CVD) and death [6]. The impact of CVD in CKD is illustrated by reports on the natural history of patients with early CKD. These indicate that the risk of premature CVD death is much higher than the risk of dialysis/transplantation progress $[7,8]$. Such observations are significant not only because of a high incidence and prevalence of end stage CKD, but because the number of patients with early CKD far exceeds those with end stage CKD. This trend is continuing to rise [9].

Patients with CKD, have the highest risk for atherosclerotic CVD. Current interventions have been insufficiently 
effective in lessening excess incidence and mortality from CVD, in CKD patients, versus other high risk groups. The mechanisms underlying the heightened risk for CVD in CKD have been the focus of intense studies and may relate to the combined effects of traditional and CKD-specific risks involving inflammation and lipid metabolism, especially the perturbation of macrophage cholesterol homeostasis [2]. Unfortunately, there is no information in current literature about the association of chronic heart failure and chronic renal failure.

The aim of our work was to find evidence supporting the theory that chronic heart failure (CHF) induces renal function damage. Therefore, serum concentration of lipids, apoAI, NTproBNP, hsCRP, LPO and creatinine were determined in patients with cardiovascular disease.

\section{MATERAL AND METHODS}

A total of 37 patients who were diagnosed with CHF according to ESC criteria, as well as 15 apparently normolipidemic healthy individuals as control, were recruited for the study. The CHF patients were hospitalized in the Department of Internal Diseases, Medical University of Lublin, Poland. Patients with liver diseases, active inflammatory diseases, acute and chronic kidney disease, malignancy, alcohol disease, thyroid diseases, unstable angina pectoris, and who had had myocardial infarction within the last three months, were excluded from the analysis. All CHF patients were on statin therapy. The patients were placed within 2 groups according to their NYHA class: patients with NYHA class $2(n=25)$, and NYHA class $3(n=12)$. This scale expresses the degree of severity of heart failure.

Written informed consents were obtained from all the participants. The study was approved by the Ethics Committee of the Medical University in Lublin, Poland, and conducted according to the principles outlined in the Helsinki Declaration.

Routine laboratory parameters were obtained in serum after 14-h overnight fasting. Blood was taken from a vein into commercial test tubes. The serum was immediately separated and stored in aliquots at $-80^{\circ} \mathrm{C}$ until use. Using routine laboratory methods, the level of creatinine and NT-proBNP, and lipids were measured by way of a Cobas Integra analyser (Germany), while concentration of hs-CRP and apoAI was assessed by immunonephelometric methods, utilizing a Simens Heath care Diagnostic Product, In addition, $\mathrm{GmbH}$ was measured on a Dade Behring nephelometer (BNII System, Germany), and Serum LPO concentration was measured using Cayman's Lipid Hydroperoxide Assay Kit (LPO). This measures the hydroperoxides directly, utilizing the redox reactions with ferrous ions. Herein, it should be noted that hydroperoxides are highly unstable and react readily with ferrous ions to produce ferric ions. The resulting ferric ions are detected by using thiocyanate ion as chromogen.

The data were expressed as medians and minimummaximum. Shapiro-Wilk's test was used to investigate whether the variables had a normal distribution. The statistical analysis of the obtained results was performed using the nonparametric Kruskal-Wallis test. The relation between concentration of LPO and creatinine level, and between level of LPO and hs-CRP concentration, as well as between level of NTproBNP and apoAI concentration, and between the level of NTproBNP and creatinine level, was examined by Spearman's correlation analysis. The statistical significance of all variables was established at $\mathrm{p}<0.05$. Statistical analysis was performed using the STATISTICA program (Stat Soft, Krakow, Poland).

\section{RESULTS}

The age, and selected blood count (hemoglobin, white blood cells and platelets), BMI and eGFR in patients with CHF are presented in Table 1.

Table 1. Age, and selected blood count, BMI and eGFR in controls and in chronic heart failure patients with NYHA2 and NYHA 3 (Media \pm SD, Median (min-max)).

\begin{tabular}{|c|c|c|c|c|}
\hline \multicolumn{2}{|c|}{ Parametr } & \multirow{2}{*}{$\begin{array}{c}\begin{array}{c}\text { Controls } \\
n=15\end{array} \\
66 \pm 9\end{array}$} & \multirow{2}{*}{$\begin{array}{c}\begin{array}{c}\text { Patients } \\
\text { with NYHA } 2 \\
n=25\end{array} \\
72 \pm 10\end{array}$} & \multirow{2}{*}{$\begin{array}{c}\begin{array}{c}\text { Patients } \\
\text { with NYHA } 3 \\
n=13\end{array} \\
70 \pm 13\end{array}$} \\
\hline & Media \pm SD & & & \\
\hline (years) & $\begin{array}{c}\text { Median } \\
\text { min-max }\end{array}$ & $\begin{array}{c}69 \\
51-81 \\
\end{array}$ & $\begin{array}{c}74 \\
51-82 \\
\end{array}$ & $\begin{array}{c}72 \\
48-89 \\
\end{array}$ \\
\hline \multirow{2}{*}{$\begin{array}{l}\mathrm{Hb} \\
(\mathrm{g} / \mathrm{dl})\end{array}$} & Media \pm SD & $12 \pm 1$ & $12.9 \pm 1.7$ & $12.4 \pm 2.6$ \\
\hline & $\begin{array}{c}\text { Median } \\
\text { min-max }\end{array}$ & $\begin{array}{c}12 \\
10-13 \\
\end{array}$ & $\begin{array}{c}13 \\
10-16 \\
\end{array}$ & $\begin{array}{c}12 \\
9-17 \\
\end{array}$ \\
\hline \multirow{2}{*}{$\begin{array}{l}\text { WBC } \\
(109 / I)\end{array}$} & Median \pm SD & $7.7 \pm 3.6$ & $9.9 \pm 4.7$ & $7.4 \pm 3.2$ \\
\hline & $\begin{array}{c}\text { Median } \\
\text { min-max }\end{array}$ & $\begin{array}{c}7.5 \\
2.8-14.2 \\
\end{array}$ & $\begin{array}{c}7,9 \\
1.3-19.8 \\
\end{array}$ & $\begin{array}{c}7,0 \\
2.6-13.2 \\
\end{array}$ \\
\hline \multirow{2}{*}{ PLT (109/I) } & Media \pm SD & $194 \pm 87$ & $246 \pm 164$ & $296 \pm 210$ \\
\hline & $\begin{array}{c}\text { Median } \\
\text { min-max }\end{array}$ & $\begin{array}{c}183 \\
73-404\end{array}$ & $\begin{array}{c}178 \\
39-730\end{array}$ & $\begin{array}{c}210 \\
119-762\end{array}$ \\
\hline & Media \pm SD & $23.7 \pm 3.1$ & $24.8 \pm 4.0$ & $24.9 \pm 3.7$ \\
\hline $\begin{array}{l}\text { BMI }\left(m^{2} /\right. \\
k g)\end{array}$ & $\begin{array}{c}\text { Median } \\
\text { min-max }\end{array}$ & $\begin{array}{c}23.4 \\
18.5-24.7\end{array}$ & $\begin{array}{c}24.5 \\
18.5-32.0\end{array}$ & $\begin{array}{c}25.0 \\
21-32 \\
\end{array}$ \\
\hline \multirow{2}{*}{$\begin{array}{l}\text { eGFR } \\
(\mathrm{ml} / \mathrm{min} / \\
\left.1.73 \mathrm{~m}^{2}\right)\end{array}$} & Media \pm SD & $108 \pm 22$ & $58 \pm 27.6$ & $35.0 \pm 14.9$ \\
\hline & $\begin{array}{c}\text { Median } \\
\text { min-max }\end{array}$ & $\begin{array}{c}108 \\
98-120\end{array}$ & $\begin{array}{c}52 * * \\
21-133\end{array}$ & $\begin{array}{c}34 * * \\
17-70\end{array}$ \\
\hline
\end{tabular}

Here, it can be seen that in patients with CHF, their lipid profiles had a significant concentration decrease of HDL cholesterol: in all patients (HDL-C 37(8-81) $\mathrm{mg} / \mathrm{dl}, \mathrm{p}=$ 0.01 ), in patients with NYHA 2 (HDL-C $37(23-81) \mathrm{mg} / \mathrm{dl}$, $\mathrm{p}=0.01$ ) and in the NYHA 3 groups (HDL-C $32(8-53) \mathrm{mg} / \mathrm{dl}$, $\mathrm{p}=0.01$ ) - as compared to the control group (vs. HDL-C $48(42-58) \mathrm{mg} / \mathrm{dl})$. Regarding the concentration of apoAI: in all patients (apoAI 103(47-164) $\mathrm{mg} / \mathrm{dl}, \mathrm{p}=0.01$ ), in patients with NYHA 2 (apoAI 115(76-150 mg/dl), $\mathrm{p}=0.01$ ) and in patients with NYHA 3 (apoAI 94(47-117 mg/dl, $\mathrm{p}=0.01$ ) - as compared to the control group (apoAI 158(142-167 mg/dl). However, statistical analysis showed no significant differences in the concentrations of other lipid parameters. The concentrations of NTproBNP, creatinine, hs-CRP and LPO are presented in Table 2. Here, the statistical analysis showed that in both groups of patients (NYHA 2 and NYHA 3), concentrations of NT-pro-BNP, hsCRP and LPO were significantly increased, in comparison to the control group. However, NYHA 3 patients had higher NT-proBNP, creatinine, hsCRP and LPO levels than did NYHA 2 patients (Table 2.) 
Table 2. Concentration of NT-proBNP, creatinine, hsCRP and lipid hydroperoxide in patients with chronic heart failure (Media \pm SD and Median (min-max))

\begin{tabular}{|c|c|c|c|c|}
\hline \multicolumn{2}{|c|}{ Parametr } & $\begin{array}{c}\text { Controls } \\
n=15\end{array}$ & $\begin{array}{c}\text { Patients } \\
\text { with NYHA } 2 \\
n=25\end{array}$ & $\begin{array}{c}\text { Patients } \\
\text { with NYHA } 3 \\
n=12\end{array}$ \\
\hline \multirow{2}{*}{$\begin{array}{l}\text { NT-proBNP } \\
(\mathrm{pg} / \mathrm{ml})\end{array}$} & Media \pm SD & $163 \pm 155$ & $2200 \pm 1503$ & $11419 \pm 10303$ \\
\hline & $\begin{array}{c}\text { Median } \\
\mathrm{X}_{\min }-\mathrm{X}_{\max }\end{array}$ & $\begin{array}{c}101 \\
55-530 \\
\end{array}$ & $\begin{array}{c}1703^{* * *} \\
631-6317 \\
\end{array}$ & $\begin{array}{c}7174^{* * *+++} \\
6500-35000\end{array}$ \\
\hline \multirow{2}{*}{$\begin{array}{l}\text { creatinine } \\
(\mathrm{mg} / \mathrm{dl})\end{array}$} & Media \pm SD & $0.99 \pm 0.34$ & $1.51 \pm 1.07$ & $1.66 \pm 0.74$ \\
\hline & $\begin{array}{c}\text { Median } \\
\mathrm{X}_{\min }-\mathrm{X}_{\max } \\
\end{array}$ & $\begin{array}{c}0.92 \\
0.57-1.28\end{array}$ & $\begin{array}{c}1.52 \\
0.6-3.6 \\
\end{array}$ & $\begin{array}{c}1.67^{*} \\
0.58-4.51\end{array}$ \\
\hline \multirow{2}{*}{$\begin{array}{l}\text { hs-CRP } \\
(\mathrm{mg} / \mathrm{l})\end{array}$} & Media \pm SD & $0.06 \pm 0.10$ & $0.47 \pm 0.39$ & $0.58 \pm 0.41$ \\
\hline & $\begin{array}{c}\text { Median } \\
\mathrm{X}_{\min }-\mathrm{X}_{\max } \\
\end{array}$ & $\begin{array}{c}0.06 \\
0.06-0.11 \\
\end{array}$ & $\begin{array}{c}0,31^{* * *} \\
0.03-1.04 \\
\end{array}$ & $\begin{array}{c}0,52^{* * *+} \\
0.02-1,04 \\
\end{array}$ \\
\hline \multirow{2}{*}{$\begin{array}{l}\text { LPO } \\
(\mu \mathrm{m} / \mathrm{ml})\end{array}$} & Media \pm SD & $0.54 \pm 0.23$ & $0.83 \pm 0.17^{* *}$ & $1.37 \pm 2.24^{* * *+}$ \\
\hline & $\begin{array}{l}\text { Median } \\
X_{\min }-X_{\max }\end{array}$ & $\begin{array}{c}0,445 \\
0.32-0.83\end{array}$ & $\begin{array}{c}0.81^{* *} \\
0.6-1.14\end{array}$ & $\begin{array}{c}1.54^{* * *+} \\
0.66-8.81\end{array}$ \\
\hline
\end{tabular}

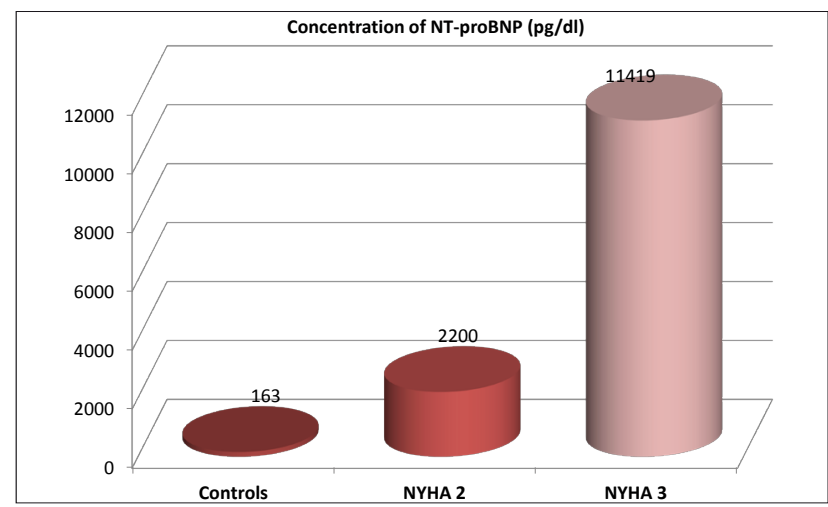

Figure 1. Concentration of NT-proBNP in chronic heart failure patients

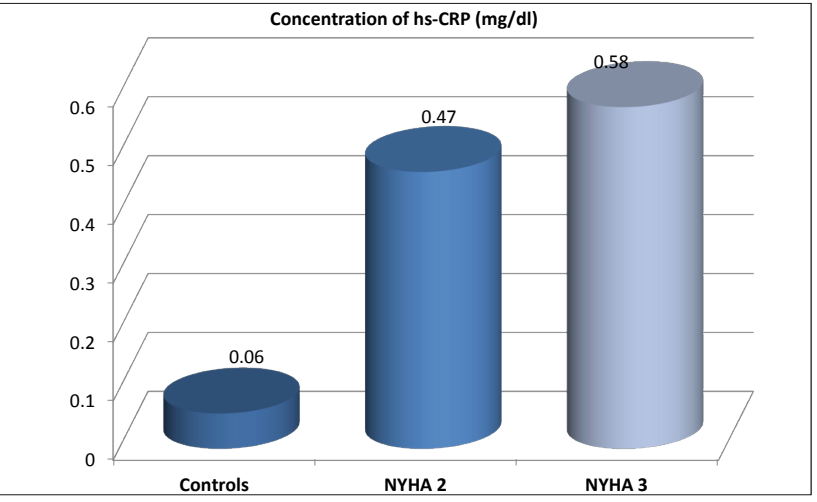

Figure 2. Concentration of hs-CRP in chronic heart failure patients

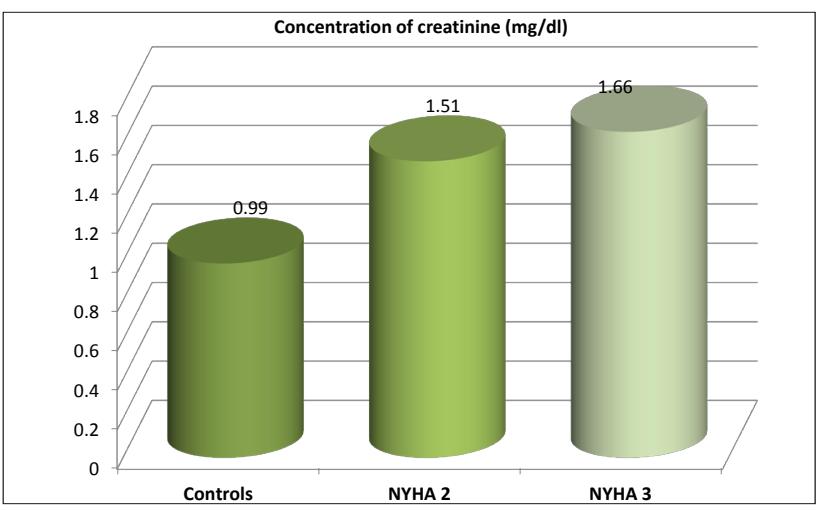

Figure 3. Concentration of creatine in chronic heart failure patients

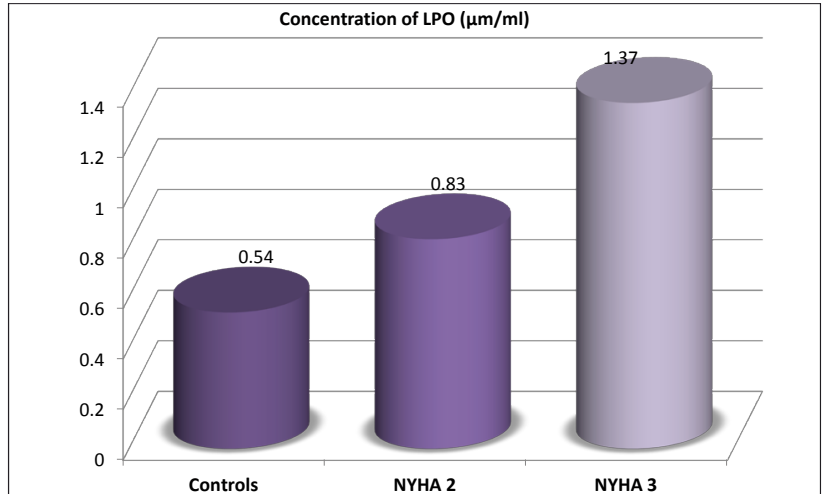

Figure 4. Concentration of LPO in patients chronic heart failure

The results revealed a significant positive correlation between LPO concentration and hs-CRP levels $(\mathrm{R}=0.792$, $\mathrm{p}=0.001)$, and between LPO concentration and creatinine levels $(\mathrm{R}=0.628, \mathrm{p}=0.05)$ in the NYHA 3 patients. Moreover, in all patients, a significant positive correlation can be seen between NTproBNP concentration and creatinine levels (Figure 5), and a significant negative correlation is noticeable between NTproBNP concentration and apoAI levels (Figure 6). Moreover, a significant negative correlation is demonstrated between the creatinine concentration and apoAI levels (Figure 7). This suggests worsening renal function in patients with $\mathrm{CHF}$.

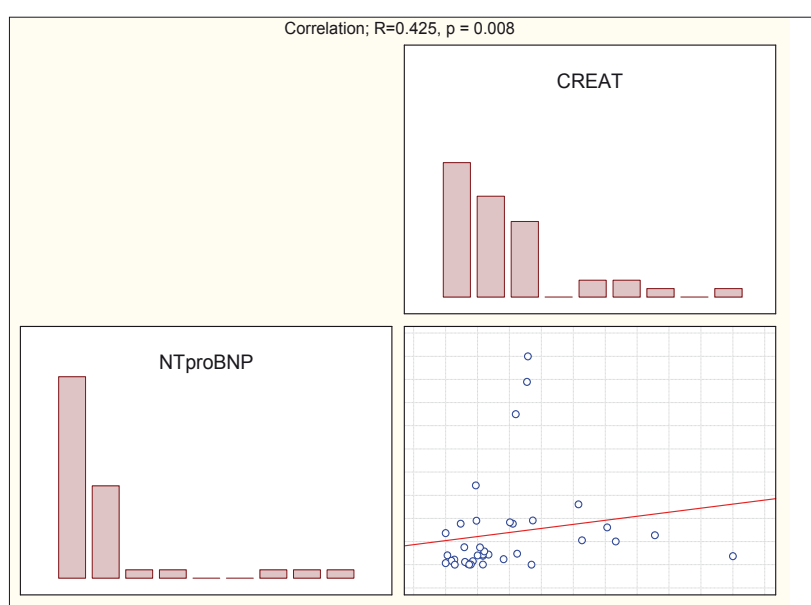

Figure 5. Correlation between NTproBNP concentration and creatinine level in chronic heart failure patients

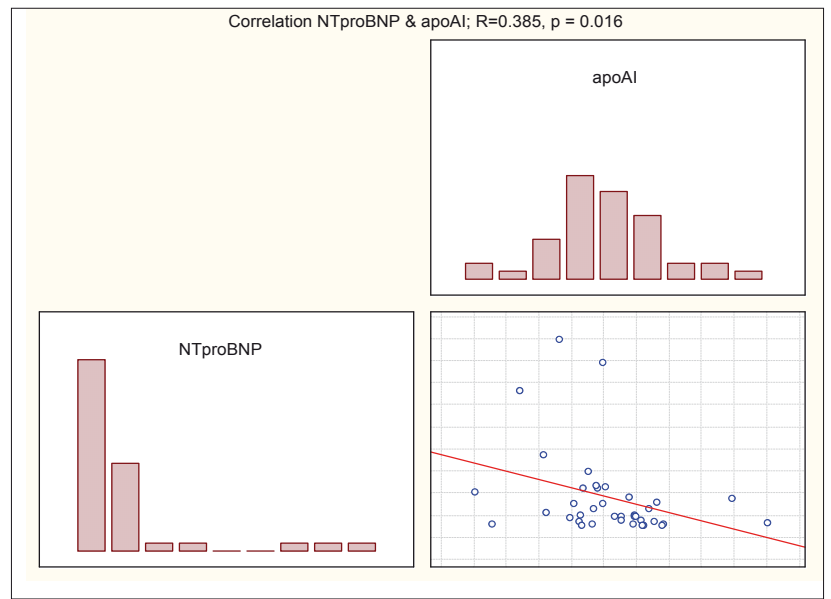

Figure 6. Correlation between NTproBNP concentration and apoAI level in chronic heart failure patients 


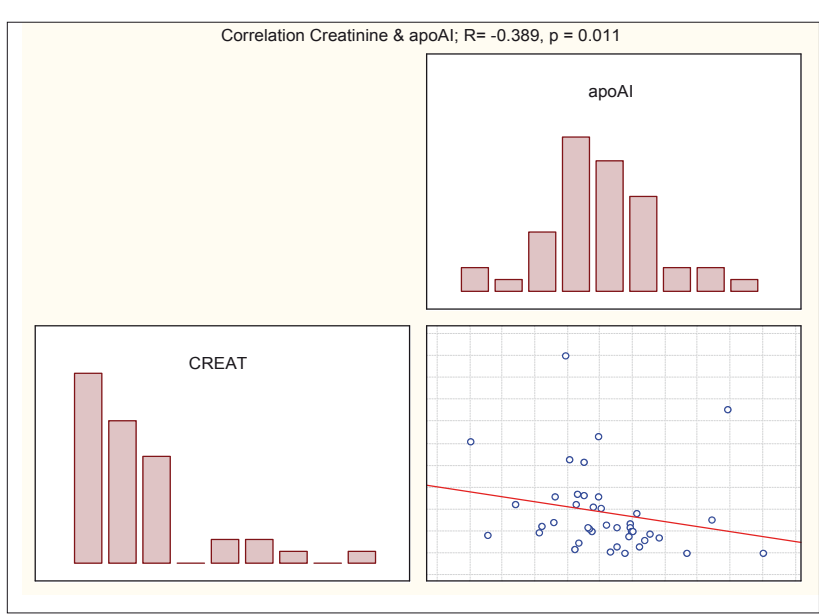

Figure 7. Correlation between creatinine concentration and apoAI level in chronic heart failure patients

\section{DISCUSSION}

Renal dysfunction is often associated with excessive CVD levels, however, it remains uncertain how the renal dysfunction/failure imparts the heightened risk [1-4]. To better understand this problem, we decided to examine the levels of creatinine, the markers of oxidative stress, inflammation and lipids, as well as apoAI, in patients with chronic heart failure. The cardiovascular risk factors that have been postulated to be especially relevant to CKD include malnutrition/low serum albumin, anemia, hyperhomocysteinemia, elevated fibrinogen, dysregulation of calcium/phosphorus, oxidative stress and inflammatory factors [4-8]. Oxidative stress and inflammation have recently gained a considerable support as factors relevant in CVD in the setting of CKD. These disturbances result from overproduction, as well as impairment in the clearance of apolipoproteinB (apoB)containing lipoproteins that reflects abnormalities in lipid substrates, enzymes, lipid transfer proteins and lipoprotein receptor activity [9-16]. Decreased HDL cholesterol has been long recognized to be a powerful negative-risk factor for CVD, and has emerged as a new target for intervention in the progression and even the regression of atherosclerosis [2]. It should be noted that low HDL-C is a consistent finding at all stages of CKD $[7,16,17]$.

The results of our study show that in patients suffering from ischemic heart disease, total cholesterol and LDL cholesterol were decreased because they were treated with statins. Yet, although statins reduce total cholesterol and LDL-C, these do not increase low HDL-C and apoAI levels, and these levels indicate a lipoprotein metabolism disorder in CHF patients [18-19]. Moreover, a higher concentration of hs-CRP and LPO can suggest that the anti-inflammatory and anti-oxidative function of HDL particles is impaired [1,18-22]. NT proBNP-a marker of left ventricular hypertrophy and cardiac dysfunction-correlates with the severity of heart failure, which is expressed via NYHA classificationas demonstrated by our research. These studies show that both NYHA 2 and 3 patients have problems, but they are particularly dangerous in the NYHA 3 patients.

Furthermore, a positive correlation between serum concentration of LPO and hsCRP, as well as LPO and creatinine levels indicates that oxidative stress affects the development of inflammation in the blood vessel wall, resulting in increased risk of cardiovascular events coming about, including myocardial infarction and renal function failure / deterioration [22]. In addiction, we have shown a positive correlation between the concentration of NTproBNP and creatinine levels, and a negative correlation between concentration of NTproBNP and apoAI levels, as well as the same between serum creatinine and apoAI levels [21]. A positive correlation between the level of NTproBNP and creatinine concentration suggests that chronic heart failure worsens renal function, while a negative correlation between serum NT-proBNP and apoAI levels indicates the impaired anti-oxidative and anti-inflammatory function of HDL particles, and progressive chronic heart failure. The negative correlation of serum creatinine and apoAI level confirms the above suggestions and also indicates that the reduced function of HDL particles may cause worsening kidney function [10-13]. The present study, hence, clearly demonstrates the important role of oxidative stress in the pathogenesis of chronic heart failure and progressive renal failure [21-23]. Beyond the aforementioned, we observed the highest serum creatinine, hsCRP, NTproBNP and LPO levels and the lowest serum apoAI and HDL-C concentrations in the NYHA 3 patients. These results suggest that the disorders act at the same time with progression of heart failure, and induce chronic renal failure.

Current literature indicates both severely reduced GFR and high albuminuria (even within currently considered normal range) are related to increased left ventricular (LV mass). Albuminuria is additionally related to LV systolic and diastolic dysfunction [24]. Worsening of renal function occurs in 30-50\% of patients hospitalised for acute heart failure (AHF), and is associated with increased mortality. Likely mechanisms involved in the decrease in renal function include impaired haemodynamics and activation of neurohormonal factors, such as the renin-angiotensinaldosterone system, the sympathetic nervous system and the arginine-vasopressin system [24]. Renal dysfunction is a frequent finding in patients with acute heart failure (AHF), and is an important prognostic factor for adverse outcomes. During an AHF event, systemic vasoconstriction and decreased cardiac function can lead to increased cardiac pre-and after load and increased left ventricular filling pressures [24]. This, in turn, leads to congestion and hypoperfusion, with neurohormonal activation, inflammation, oxidative stress and haemodynamic abnormalities, leading to organ dysfunction, including renal dysfunction $[24,25]$.

\section{CONCLUSION}

The study results suggest that disorders in serum concentrations of NTproBNP, LPO, hsCRP, apoAI and creatinine levels, and progressive heart failure gradually accompany progressive chronic renal failure. Such disorders may lead to cardiovascular events and to renal failure, consequently, to patient death. 


\section{REFERENCES}

1. Koenig W., High-sensitivity C-reactive protein and atherosclerotic disease: from improved risk prediction to risk-guided therapy. Int. J. Cardiol., 168, 5126, 2013.

2. Yamamoto S., Kon V. Mechanisms for increased cardiovascular disease in chronic kidney dysfunction. Curr. Opin. Nephrol. Hypertens., 18, 181, 2009.

3. Foley RN., Parfrey PS., Sarnak MJ. Epidemiology of cardiovascular disease in chronic renal disease. J.Am. Soc.Nephrol., 9, S16, 1998.

4. Anavekar NS., McMurray JJ., Velazquez EJ, et al. Relation between renal dysfunction and cardiovascular outcomes after myocardial infarction. N. Engl. J. Med., 351, 1285, 2004.

5. Klausen KP., Scharling H., Jensen JS. Very low level of microalbuminuria is associated with increase of risk of death in subjects with cardiovascular or cerebrovascular diseases. J. Intern. Med., 260, 231, 2006.

6. Keith DS., Nichols GA., Gullion CM., et al. Longitudinal follow-up and outcomes among a population with chronic kidney disease in a large managed care organization. Arch. Intern. Med., 164, 659, 2004.

7. Weiner DE., Tighiouart H., Elsayed EF., Griffith JL., Salem DN., Levey AS., Sarnak MJ. The relationship between non-traditional risk factors and outcomes in individuals with stage 3 to 4 CKD. Am. J. Kidney Dis., 51, 212, 2008.

8. Kalantar-Zadeh K., Block G., Horwich T., Fonarow GC. Reverse epidemiology of conventional cardiovascular risk factors in patients with chronic heart failure. J. Am. Coll. Cardiol., 43, 1439, 2004.

9. Tsimihodimos V., Dounousi E., Siamopoulos KC. Dyslipidemia in chronic kidney disease: an approach to pathogenesis and treatment. Am. J. Nephrol., 28, 958, 2008.

10. Chan DT., Irish AB., Dogra GK., Watts GF. Dyslipidaemia and cardiorenal disease: mechanisms, therapeutic opportunities and clinical trials. Atherosclerosis, 196, 823, 2008.

11. Okubo K., Ikewaki K., Sakai S., Tada N., Kawaguchi Y., Mochizuki S. Abnormal HDL apolipoprotein A-I and A-II kinetics in hemodialysis patients: a stable isotope study. J. Am. Soc. Nephrol., 15, 1008, 2004.

12. Navab M., Reddy S., Van Lenten BJ., Anantharamaiah GM., Fogelman AM. Role of dysfunctional HDL in atherosclerosis. J. Lipid. Res., 50, S145, 2009.

13. Boden WE. High-density lipoprotein cholesterol as an independent risk factor in cardiovascular disease: assessing the data from Framingham to the Veterans Affairs High: Density LipoproteinIntervention Trial. Am. J. Cardiol., 86, 19L, 2000.

14. Kimak E., Hałabiś M., Baranowicz-Gąszczyk I. Relationship between serum lipid, lipoprotein, triglyceride-rich lipoprotein, and highdensity lipoprotein particle concentrations in post-renal transplant patients. J. ZUS-B, 11, 249, 2010
15. Kimak E., Hałabiś M., Baranowicz-Gąszczyk I., Solski J., Książek A. Association between moderately oxidized low-density lipoprotein and high-density lipoprotein particle subclass distribution in hemodialyzed and post-renal transplant patients. J. ZUS-B., 12, $365,2011$.

16. Kimak E., Bylina J., Solski J., Hałabis' M., Baranowicz-Gaąszczyk I., Ksiażek A. Association between lipids, lipoproteins composition of HDL particles and triglyceride-rich lipoproteins, and LCAT and CETP activity in post-renal transplant patients. Cell. Biochem. Biophys. 67, 695, 2013.

17. Luis F., Ramos LF., Shintani A., Ikizler TA., Himmelfarb J. Oxidative stress and inflammation are associated with adiposity in moderate to severe CKD. J. Am. Soc. Nephrol. 19, 593, 2008.

18. Li H, Horke S, Feorstermann U. Vascular oxidative stress, nitric oxide and atherosclerosis. Atherosclerosis, 237, 208, 2014.

19. Rosenson R. S., Stafforini D. M., Modulation of oxidative stress, inflammation, and atherosclerosis by lipoprotein-associated phospholipase A2. J. Lipid. Res. 53, 1767, 1782. 2012.

20. Tousoulis D., Psaltopoulou T., Androulakis E., Papageorgiou N, Papaioannou S, Oikonomou E, Synetos A, Stefanadis Ch. Oxidative stress and early atherosclerosis: novel antioxidant treatment. Cardiovasc. Drugs. Ther., 29, 75, 2015.

21. Shlipak MG., Fried LF., Cushman M., Manolio TA., Peterson D., Stehman-Breen C., Bleyer A., Newman A., Siscovick D., Psaty B. Cardiovascular mortality risk in chronic kidney disease: comparison of traditional and novel risk factors. JAMA., 293, 1737, 2005.

22. LaRosa JC., Grundy SM., Waters DD., Shear C., Barter P., Fruchart JC., Gotto AM., Greten H., Kastelein JJ., Shepherd J., Wenger N. Intensive lipid lowering with atorvastatin in patients with stable coronary disease. N. Engl. J. Med., 352, 1425, 2005.

23. MatsushitaK., Ballew SH., Coresh J. Influence of Chronic Kidney Disease on Cardiac Structure and Function. Curr. Hypertens. Rep, 17, 581, 2015, doi:10.1007/s11906-015-0581-x.

24. Schmieder RE., Mitrovic V., Hengstenberg V. Renal impairment and worsening of renal function in acute heart failure: can new therapies help? The potential role of serelaxin. Clin. Res. Cardiol., 104, 621, 2015.

25. Guazzi M., Gatto P., Giusti G., Pizzamiglio F., Previtali I., Vignati C., Arena R. Pathophysiology of cardiorenal syndrome in decompensated heart failure: role of lung-right heart-kidney interaction. Int. J. Cardiol., 169, 379, 2013. 